\title{
Using a screening tool to identify the auditory behavior of students who are learning to read and write
}

\author{
Giulia Ádni Viana Santos ${ }^{1}$ \\ https://orcid.org/0000-0002-6848-9928 \\ Maria Luiza Lopes Timóteo de Lima ${ }^{1}$ \\ https://orcid.org/0000-0001-8600-0017 \\ Manoelina Xavier Cavalcante ${ }^{2}$ \\ https://orcid.org/0000-0003-1639-4027 \\ Leonardo Gleygson Angelo Venâncio' 1 \\ https://orcid.org/0000-0002-1971-755X \\ Cleide Fernandes Teixeira ${ }^{1}$ \\ https://orcid.org/0000-0001-9869-4431
}

Universidade Federal de Pernambuco UFPE, Recife, Pernambuco, Brasil.

Escola de Formação e Aperfeiçoamento de Educadores do Recife Professor Paulo Freire, Recife, Pernambuco, Brasil.

This study was carried out in the SpeechLanguage-Hearing Sciences undergraduate program at the Universidade Federal de Pernambuco - UFPE, Recife, Pernambuco, Brazil.

Conflict of interests: Nonexistent

\section{(c) (i)}

Received on: July 2, 2021

Accepted on: September 28, 2021

Corresponding address:

Giulia Adni Viana Santos

Avenida Professor Chaves Batista, 262

Várzea

CEP: 50740-030 - Recife, Pernambuco,

Brasil

E-mail: giuliadni@hotmail.com

\section{ABSTRACT}

Purpose: to analyze the use of a screening tool, by teachers, to identify the auditory behavior of students who are learning to read and write.

Methods: a cross-sectional study including 22 students who answered the Fisher's Auditory Problems Checklist (QFISHER). The analysis of this questionnaire approached the categories of hearing, attention, memory, language, and school performance. The chi-square statistical test and Mann-Whitney test were used to compare the scores between the age groups, considering the $5 \%$ significance level.

Results: school performance had the worst frequency in QFISHER (87.72\%), followed by attention (62.10\%), language (60.53\%), and hearing (59.65\%). The median revealed worse assessment in school performance (100.0\%) followed by attention (60.0\%). The QFISHER overall score was $66.7 \%$. The comparison between age groups did not reveal any significant difference for the domains assessed.

Conclusion: the QFISHER, used by teachers, as a screening tool for children who are learning to read and write, can identify behavioral changes suggestive of auditory processing disorder, broadening the possibility of early interventions.

Keywords: Literacy; Audiology; Learning Disabilities; Surveys and Questionnaires; Auditory Perception; Hearing Disorders 


\section{INTRODUCTION}

Studies in Brazil point to a high number of children with learning difficulties, particularly written language ${ }^{1-3}$. The causes of school failure go beyond pedagogical issues - whether they are appropriate to children - and include policies for them and the environment where they live - which is often inadequate to their development. Data from the 2016 School Census showed that $57.8 \%$ of the Brazilian schools had students with a disability, who attend regular classes ${ }^{4}$.

Hearing, language, and learning are interfaced. Hence, the integrity of the central nervous system, the sustained selective attention skills, auditory perception and discrimination skills, short- and long-term memory, phonological awareness, and so forth are necessary, for instance, to reading comprehension ${ }^{5-7}$. Thus, in terms of hearing, children with sensory deficits (hearing loss) are not the only ones that may have problems. Someone may have auditory processing (AP) difficulties, for example, even with normal peripheral hearing (normal audiogram) ${ }^{6}$.

AP consists of mechanisms and processes of the central auditory system responsible for various behavioral phenomena, including speech and language. It encompasses a set of auditory skills and competencies necessary to the detection, localization, lateralization, discrimination, and recognition of auditory patterns (competing and degraded acoustic signals) and sound information ${ }^{8}$.

In this context, the auditory processing disorder (APD) is the impaired development of the communicative functions related to oral and/or written expression and/or comprehension, impacting academic performance. Indeed, learning problems are more properly noticed in the classroom ${ }^{9}$.

The signs of learning disorders involve APD, which is characterized by an impaired ability to understand, discriminate, recognize, recall, and/or comprehend information presented to the auditory structures, even with normal intelligence and peripheral hearing ${ }^{10}$. APD is classically related to how we analyze, classify, organize, and interpret acoustic events - i.e., what we do with what we hear?

Children with APD have school and communication complaints, including the incapacity to follow complex verbal instructions and the presence of poor verbal cognitive performance compared with nonverbal performance, reading and writing difficulties, language delay, competing sound difficulties, and attention difficulties when presented to auditory information ${ }^{8}$.
Learning difficulties are common problems at school and may occur regardless of having normal intelligence, absence of sensory or neurological problems, adequate school teaching, and sufficient sociocultural opportunities ${ }^{4}$. The main causes of learning difficulties are doubtless pedagogical in nature and may take place at both school and home ${ }^{4}$.

Including routine questionnaire or screening procedures sensitive to identify actual hearing difficulties has proved to be indispensable in speech-language-hearing therapy. In 1996, the American Speech-LanguageHearing Association (ASHA) task force on central APD approached the need for universally accepted screening tools for children. More recently, the British Society of Audiology highlighted the importance of having parents and/or teachers administer validated questionnaires to screen the auditory processing of people at risk of APD ${ }^{11}$.

Behavioral questionnaires that assess AP make it possible to identify qualitative everyday information that may be related to APD. Some of these stand out, namely: the Children's Auditory Performance Scale ${ }^{12}$, Children's Home Inventory of Listening Difficulties ${ }^{12}$, and Fisher's Auditory Problems Checklist (QFISHER) ${ }^{13}$. The routine use of this type of screening can help identify children who would benefit from formal AP assessment.

The QFISHER reveals data on overall characteristics associated with AP skill categories, guided by the following principles: It includes problems related to all AP components; it uses simple language; it is quick and easy to administer and interpret; it distinguishes people with normal and abnormal AP; it can be filled out by any source of reference (parent, teacher, speech-language-hearing therapist); it can be used as a screening tool ${ }^{13,14}$.

An exploratory study on the usefulness of the QFISHER concluded that it can be used as a tool to screen children with APD, as those who scored $28 \%$ (seven points) in the questionnaire were significantly more prone to being diagnosed with APD, according to the Buffalo model diagnostic test battery ${ }^{14}$.

The QFISHER has been translated into a Brazilian version and divided into subareas. The auditory functioning scale has 24 questions that furnish data on behavioral difficulties manifested in the person's daily life, considering the following subareas: hearing, attention, memory, language, and school performance ${ }^{15}$. Thus, it enables a broad understanding of the auditory behavior associated with the processes 
involved in AP. A study with 19 people (aged 12 to 15 years old) diagnosed with APD used the QFISHER to monitor the evolution of their auditory behavior after auditory training. It found a statistical difference in the total score with a decrease in auditory complaint score halfway through the training and at its end. They suggested that the questionnaire can be used to monitor the auditory behavior during an intervention ${ }^{15}$.

Given the complexity of school learning, elementary and middle school teachers should be able to identify children with learning difficulties, particularly those with auditory skill disorders, including APD. Children with hindered learning often have school complaints; hence, identifying these difficulties immediately helps develop strategies to potentialize the teaching-learning process.

Therefore, APD must be identified at school as early as possible. On the other hand, teachers at the Municipal School System of Recife, Brazil, may be unacquainted with aspects related to AP and its relevance to learning. The objective of this study was to analyze the teachers' use of a screening tool to identify the students' auditory behavior while learning to read and write.

\section{METHODS}

This is a descriptive, observational, cross-sectional study, approved by the Research Ethics Committee of the Universidade Federal de Pernambuco (Federal University of Pernambuco - UFPE), Brazil, under protocol no. 2.622.355. It was carried out in 2018, in Recife, with municipal school first- to third-grade classroom teachers whose students were learning to read and write. The study had two stages. The first one encompassed 40 teachers who took a course named Auditory Processing: Essentials for Teachers, offered by the Speech-Language-Hearing Sciences program at UFPE in partnership with the Professor Paulo Freire Teachers' Training School of Recife. The objective was to train them to administer the QFISHER screening tool $^{15}$ (Annex 1 ) and identify qualitative information on the students' everyday life that may be related to signs of APD. In the second stage, the 12 teachers who had finished the course chose 22 students based on the QFISHER. The exclusion criterion was students with comorbidities - i.e., cognitive disorders, specific language disorder (SLI), or attention-deficit/hyperactivity disorder (ADHD). The teachers' sociodemographic data reveal a mature group, with a mean age of 43.68 years $(S D=7.87)$. All of them were females, who had been teaching for 3 to 26 years $(M=13.22$; $S D=7.06)$, $76.67 \%$ of them with a specialization, $3.33 \%$ with a master's degree, and $20 \%$ with a bachelor's degree.

The QFISHER analysis was made following criteria proposed by Cibian and Pereira ${ }^{15}$, considering the score of the five subareas: hearing (9 points); attention (5 points); memory ( 3 points); language (4 points); school performance (3 points). The total score is 24 points, with one point for each item checked. If seven or more items are checked (28\%), the person is considered at risk of APD, and the recommended procedure is a clinical AP assessment. The cases that scored seven or less were excluded from the analysis as they did not indicate a risk of APD.

The data were analyzed with SPSS software, version 18. To assess the students' year in school, age, and the QFISHER subareas, the percentage frequencies were calculated, and the respective frequency distributions were constructed. Also, the chi-square and Mann-Whitney tests were applied to compare the scores between the age groups. All conclusions were based on the $5 \%$ significance level.

\section{RESULTS}

Risk of APD was found in 19 (86.36\%) out of the 22 students screened with the QFISHER, while the other three $(17 \%)$, whose score was below seven points, were excluded from the analysis because they were not classified as at risk of APD. Regarding the sociodemographic profile, $40.91 \%$ of the 19 students who comprised the sample were males, while $59.09 \%$ were females. Most of them were 7 years old and were in first grade. The proportion comparison test was not significant, indicating a similar number of students in the first, second, and third grades, as well as those 7 years old and 8 to 9 years old (Table 1 ). 
Table 1. Distribution of age and grade in school of students at risk of auditory processing disorder $(\mathrm{N}=19)$

\begin{tabular}{lccc}
\hline Variable & $\mathbf{n}$ & $\%$ & p-value $^{1}$ \\
\hline Grade in school & 7 & 36.8 & \\
1st & 6 & 31.6 & 0.949 \\
2nd & 6 & 31.6 & \\
3rd & & & \\
Age group & 11 & 57.9 & 0.491 \\
7 years & 8 & 42.1 & \\
8 to 9 years
\end{tabular}

${ }^{1} \mathrm{p}$-value of the chi-square test for proportion comparison

Considering the overall classification of the five QFISHER subareas, school performance had the highest absolute frequency $(87.72 \%)$, followed by attention $(62.10 \%)$, language $(60.53 \%)$, and hearing (59.65\%). The distribution of the median, analyzed to better understand the values without distortions, is shown in Table 2. In general, the students' total score in the QFISHER was $66.7 \%$. The proportion comparison test regarding the QFISHER percentage score between the age groups was not significant in the domains assessed, indicating that there was no significant difference.

Table 2. Distribution of the median total score of the subareas assessed with the Fisher's Auditory Problems Checklist (QFISHER) of the students at risk of auditory processing disorder $(\mathrm{N}=19)$

\begin{tabular}{lcccccc}
\hline \multirow{2}{*}{ Subarea } & \multicolumn{3}{c}{ Statistics } & \multicolumn{3}{c}{ Median \% per age } \\
\cline { 2 - 7 } & $\begin{array}{c}\text { Score } \\
\text { variation }\end{array}$ & Median & $\%$ & $\mathbf{7}$ years & $\mathbf{8}$ to 9 years & p-value $^{1}$ \\
\hline Hearing & $0-9$ & 5.00 & 55.6 & 66.7 & 55.6 & 0.530 \\
Attention & $0-5$ & 3.00 & 60.0 & 80.0 & 50.0 & 0.091 \\
Memory & $0-3$ & 1.00 & 33.3 & 33.3 & 50.0 & 0.608 \\
Language & $0-4$ & 2.00 & 50.0 & 75.0 & 50.0 & 0.443 \\
School performance & $0-3$ & 3.00 & 100.0 & 100.0 & 100.0 & 0.543 \\
Total & $0-24$ & 16.00 & 66.7 & 75.0 & 47.9 & 0.406 \\
\hline
\end{tabular}

${ }^{1} \mathrm{p}$-value of the Mann-Whitney test

Concerning the frequency of the questions in the five QFISHER subareas, all of them were checked. Some aspects stand out, such as the students' difficulties remembering sequence, their short attention spans, distractions with sounds at school, the lack of attention to verbal instructions, and difficulties remembering what they heard in the previous week. They also had difficulties understanding spoken messages. Most students' school performance was below the average, with evidence of reading comprehension difficulties (Table 3). 
Table 3. Distribution of questions per subareas of the Fisher's Auditory Problems Checklist (QFISHER) of the students at risk for auditory processing disorder $(\mathrm{N}=19)$

\begin{tabular}{lcccc}
\hline Categories assessed $^{1}$ & \multicolumn{3}{c}{ Yes } & \multicolumn{2}{c}{ No } \\
\cline { 2 - 5 } Subarea: hearing & $\mathbf{n}$ & $\%$ & $\mathbf{n}$ & $\%$ \\
2. Does not attentively listen to instructions & & & & \\
3. Says: "huh?" and "what?" at least 5 times & 10 & 52.6 & 9 & 47.4 \\
8. Has difficulties with the language sounds & 6 & 31.6 & 13 & 68.4 \\
9. Has problems discriminating sounds & 10 & 52.6 & 9 & 47.4 \\
10. Has difficulties recalling the sequence heard from someone & 11 & 57.9 & 8 & 42.1 \\
14. Has difficulties following auditory instructions & 17 & 89.5 & 2 & 10.5 \\
17. Responds slowly or late to verbal stimuli & 15 & 78.9 & 4 & 21.1 \\
20. Cannot relate what they heard to what seems to be & 14 & 73.7 & 5 & 26.3 \\
21. Learns little by hearing & 10 & 52.6 & 9 & 47.4 \\
Subarea: attention & 10 & 52.6 & 9 & 47.4 \\
1. Does not pay attention to 50\% or more of the instructions & & & & \\
4. Cannot focus on auditory stimuli for more than a few seconds & 12 & 63.2 & 7 & 36.8 \\
5. Has a short attention span & 6 & 31.6 & 13 & 68.4 \\
6. Sometimes daydreams (gets distracted) & 15 & 78.9 & 4 & 21.1 \\
7. Gets easily distracted with background sounds & 11 & 57.9 & 8 & 42.1 \\
Subarea: memory & 15 & 78.9 & 4 & 21.1 \\
11. Forgets what was said a few minutes before & & & & \\
12. Does not remember simple things of their everyday routine & 11 & 57.9 & 8 & 42.1 \\
13. Has problems remembering what they heard in the previous week, month, year & 6 & 31.6 & 13 & 68.4 \\
Subarea: language & 12 & 63.2 & 7 & 36.8 \\
15. Often does not understand what others say & & & & \\
16. Does not understand many words - verbal concepts or the age or grade in school & 16 & 84.2 & 3 & 15.8 \\
18. Has language problems & 10 & 52.6 & 9 & 47.4 \\
19. Has articulation problems & 9 & 47.4 & 10 & 52.6 \\
Subarea: school performance & 11 & 57.9 & 8 & 42.1 \\
22. Lacks learning motivation & & & & \\
23. Has a performance below the average in one or more areas & 13 & 68.4 & 6 & 31.6 \\
24. Has difficulties with reading comprehension & 19 & 100.0 & 0 & 0.00 \\
\hline & 18 & 94.7 & 1 & 5.3 \\
\hline
\end{tabular}

Base $^{1}$ - Considering that there is more than one answer to the same student, the basis is recorded for percentage calculation, instead of the total $(N=19)$.

As for the open-ended questions, of the 19 students at risk of APD, the ones who did not have difficulties with the language sounds $(n=8)$, in question 8 , and who did not lack learning motivation $(n=6)$, in question 22, were excluded. Question 8 identifies what reading method the teacher uses when the student has difficulties with the language sounds, and it was verified that the most used one was asking the student to repeat it aloud. As for behaviors related to learning motivation, the students' degree of inattention and/or distraction in the classroom stands out (Table 4). 
Table 4. Analysis of the open-ended questions of the Fisher's Auditory Problems Checklist (QFISHER)

\begin{tabular}{llc}
\hline Question $\mathbf{8}(\mathbf{N}=1 \mathbf{1 1})$ & $\mathbf{n}$ & $\%$ \\
\hline What reading method is used? & 3 & 27.27 \\
The teacher reads & 5 & 45.45 \\
The student reads aloud & 3 & 27.27 \\
The letter/syllable is pronounced & $\mathrm{n}$ & $\%$ \\
Question 22 (N=13) & & \\
Observed behavior reveals a lack of learning motivation & 3 & 23.07 \\
Their attention is called & 6 & 46.15 \\
Is distracted in class & 4 & 30.76 \\
Dependency for activities & & \\
\hline
\end{tabular}

The most prevalent aspects that directed the teachers to choose the students for screening $(n=22)$ were their distraction and language problems (morphology, syntax, vocabulary, inverted writing) in the classroom (Table 5).

Table 5. Distribution of the main aspects considered in students screening with Fisher's Auditory Problems Checklist $(\mathrm{N}=22)$

\begin{tabular}{lcc}
\hline Aspects & $\mathbf{n}$ & \% \\
\hline Distraction/inattention in the classroom & 06 & 27.27 \\
Inverted letters & 04 & 18.18 \\
Language problems & 06 & 27.27 \\
Articulation problems & 02 & 9.09 \\
Does not understand in the classroom & 04 & 18.18 \\
\hline
\end{tabular}

\section{DISCUSSION}

The high failure rate in third grade (typically, when the student is 8 years old and finishes the process of learning to read and write) and in the first years of middle and high school in public schools causes concern $^{4}$. Associated with this factor, the new generation of students connected to various technologies has doubtless posed a challenge to teachers' training, especially in continuing education. Moreover, it is a greatly important current topic for public education policies, given the possibility of both formal and informal learning in the digital era ${ }^{16}$. The teacher is responsible for the tough task of identifying the students' difficulties in the classroom that result in their low achievements ${ }^{9}$.

In this study, the screening tool used in the classroom guided the teachers more objectively in observing and identifying the cases with signs of APD. Factors pointed out by the teachers, such as distraction and language problems (morphology, syntax, vocabulary, and inverted writing), corroborate this statement. There were, however, five cases selected without signs of auditory skill disorder typical of AP - e.g., the mother suspects their child has a disability (referral for assessment with a neurologist); the child behaves differently (yells when it is noisy or is quite unstable emotionally); constantly has earaches; does not learn to read and write; does not perform any task they are asked to; and barely speaks. Regarding the cases with comorbidities, it is inferred that the teacher did not distinguish the memory auditory attention skills from overall memory and attention aspects.

The results showed that school performance was the subarea with the worst frequency. This is expected, due to the high inattention rate $(62.10 \%)$, associated with weak language performance $(60.53 \%)$ and spoken message processing (59.65\%). Common characteristics in children before they learn to read and write, such as difficulties memorizing verses, learning songs, telling stories, rhyming, developing narratives, and so forth, may be signs of AP difficulties.

Based on this finding, the possibility of perception bias on the part of the teachers cannot be dismissed. 
However, they had been previously trained to properly administer the instrument. Moreover, previous studies show that, even when administered by the parents, caregiver, or speech-language-hearing therapists, this category may be impaired ${ }^{13-15}$. Given these two facts, such bias has probably not occurred.

According to Martins, Pinheiro, and Blasi ${ }^{17}$, APD affects the interpretation of sound patterns and can hinder information comprehension and cause behavior changes, consequently leading to school failure. The auditory skills help understand speech (even with poor sound quality), keep on listening for a given time, discern whether two sound stimuli are different or the same, identify the direction and distance of the sound source, and establish the correspondence between a sound, its sources, and its meanings ${ }^{8}$.

Concerning open-ended question 8 , the reading method used with this population noticeably involves the student's participation in reading aloud, either continuously or syllable by syllable. According to Pinheiro and Rothe-Neves ${ }^{17}$, this method gives the child cues on the grapheme-phoneme association, information on the effects of a varying number of letters (length effect) on reading, the effects of varying word familiarity levels on reading and writing, and the involvement of the semantic process. The lack of learning motivation was revealed in the distracting behavior in the classroom, once again pointing out attention as an important component in the learning process. According to Moraes ${ }^{18}$, attention is maintained by the person's interest in something they want, which motivates them enough to overcome the resistance. Hence, the teacher can choose strategies that arouse the children's interest.

The lack of attention occurred more frequently in this study in short attention spans, easy distraction with background noise, and little listening attention. According to Larimer $^{19}$, children with APD have changes specifically related to listening attention. This condition sharpens everyday difficulties in the oral communication process and causes academic loss - hence, these people commonly have some type of social adjustment difficulty.

In the language category, there was a prevalence of "The child often does not understand what we say". The causal relationship between language problems and APD, particularly in terms of oral language comprehension confirmed in some studies ${ }^{20,21}$, agrees with this finding and explains it. Characteristics that cause difficulties decoding sounds can associate with changes in reading and writing. This is so in phonological disorders, in which similar-sounding words (voiced and voiceless) are switched or letters are inverted. Difficulties can accompany other AP changes ${ }^{3,5,20}$.

The most frequent item in the results regarding memory was "The child has trouble remembering what they heard in the previous week, month, year", followed by "The child forgets what was said a few minutes before". This reveals the auditory memory impairment in people with signs of APD. According to Pires, Mota, and Pinheiro ${ }^{22}$, children with APD and phonological awareness difficulties also present with changes in cognitive aspects, such as working, declarative, and procedural memory systems. The auditory skills also help the sequential memory and the organization of auditory stimuli to plan responses.

According to Moore ${ }^{23}$, the central auditory function goes beyond a map of the central nervous system to the auditory portion. It involves a complex sound transformation process in the cochlea and the efferent and processing pathways in the brain. Moreover, the structures outside the posterior temporal lobe play a role in understanding the spoken message, "hearing and listening". Thus, satisfactory learning requires fully synchronous biopsychosocial factors, creating favorable conditions for this process. When learning is not satisfactory, the various causes that might have hindered it must be considered and understood in the search for solutions ${ }^{15}$.

A continuing education program should be established for teachers at the Municipal School System of Recife, addressing auditory skills and their relationship with learning.

\section{CONCLUSION}

The results of this research show that the QFISHER can identify behavioral changes suggestive of APD, broadening the possibility of early interventions in students. Having the teachers use the QFISHER in this study enabled a more effective perception of the students' everyday qualitative information that may be related to signs of APD. 


\section{REFERENCES}

1. Luiz J, Sylvia Z, Ciasca M, Jaime C, Zorzi L. Alterações ortográficas: existem erros específicos para diferentes transtornos de aprendizagem? Psicopedagogia. 2009;26(80):254-64.

2. Paterlini LSM, Zuanetti PA, Pontes-Fernandes AC, Fukuda MTH, Hamad APA. Screening and diagnosis of learning disabilities/disorders outcomes of interdisciplinary assessments. Rev. CEFAC. 2019;21(5):e13319.

3. Gonçalves-Guedim TF, Capelatto IV, SalgadoAzoni CA, Ciasca SM, Crenitte PAP. Performance of children with attention deficit hyperactivity disorder in phonological processing, reading and writing. Rev. CEFAC. 2017;19(2):242-52.

4. Brasil. Censo escolar da educação básica 2016: notas estatísticas. Ministério da Educ. 2017;

5. Wiemes GRM, Kozlowski L, Mocellin M, Hamerschmidt R, Schuch LH, Wiemes GRM et al. Potencial evocado cognitivo e desordem de processamento auditivo em crianças com distúrbios de leitura e escrita. Braz J Otorhinolaryngol. 2012;78(3):91-7.

6. Vilela N, Barrozo T, Pagan-Neves L, Sanches S, Wertzner $\mathrm{H}$, Carvallo R. The influence of (central) auditory processing disorder on the severity of speech-sound disorders in children. Clinics. 2016;70(2):62-8.

7. Pereira LD. Introdução ao processamento auditivo central. In: Balen AS, editor. ABA: Tratado de audiologia. São Paulo: Ed Santos; 2011. Cap. 17. p.279-91.

8. Bellis TJ. Assessment and management of central auditory processing disorders in the educational setting: from science to practice. Plural Publishing; 2011.

9. Costa RS. Rastreio de perturbações de comunicação num agrupamento de escolas [thesis]. Aveiro (Portugal): Universidade de Aveiro; 2011.

10. ASHA: American Speech-Language-Hearing Association. (Central) Auditory processing disorders: technical report. [homepage on the internet]. 2005. [accessed 2021 May 2]. Available at: https://www.asha.org/policy/TR2005-00043/.

11. Moore D, Campbell N, Rosen S, Bamiou D-E, Sirimanna T, Grant $P$ et al. British Society of Audiology Position Statement \& Practice Guidance: Auditory Processing Disorder (APD). 2018.
12. Schow RL, Seikel JA. Screening for (central) auditory processing disorder. Handb Audit Process Disord Audit Neurosci diagnosis. 2007;1:137-59.

13. Fisher L. Fisher's auditory problems checklist. Bemidji, MN Life Prod. 1976.

14. Strange AK, Zalewski TR, Waibel-Duncan MK. Exploring the usefulness of Fisher's Auditory Problems Checklist as a screening tool in relationship to the Buffalo Model Diagnostic Central Auditory Processing Test Battery. J Educ Audiol. 2009;15(1)44-52.

15. Cibian AP, Pereira LD. Questionnaire for use in the monitoring of auditory training results. Distúrb. Comun. 2015;27(3):466-78.

16. Tavares $\mathrm{V}$ dos $\mathrm{S}$, Melo RB de. Possibilities for formal and informal learning in the digital era: what does the digital native youth think?. Psicol Esc e Educ. 2019;23(1):1-9.

17. Martins JS, Pinheiro MMC, Blasi HF. A utilização de um software infantil na terapia fonoaudiológica de distúrbio do processamento auditivo central. Rev. Soc Bras Fonoaudiol. 2008;13(4):398-404.

18. Moraes CR, Varela S. Motivação do estudante durante o processo de ensino-aprendizagem. Rev Eletrônica Educ. 2007;1(1):1-15.

19. Larimer MP. Attention deficit hyperactivity disorder (ADHD) research developments. Nova Publishers; 2005.

20. De Araujo ECM, Guimarães FF. Auditory processing disorder $\mathrm{x}$ reading and writing difficulty: is there a relationship? Rev Pós-Graduação do Cent Univ Cid Verde. 2018;4(1):1-15.

21. dos Santos MS, dos Santos SS, Lourinho LA. The importance of early identification of central auditory processing disorder and its interferences in learning. Res Soc Dev. 2020;9(9):1-17.

22. Pires MM, Mota MB, Pinheiro MMC. The memory systems of children with (central) auditory disorder. CoDAS. 2015;27(4):326-32.

23. Moore DR. Auditory processing disorder (APD): Definition, diagnosis, neural basis, and intervention. Audiol Med. 2006;4(1):4-11. 


\section{ANNEX 1. FISHER'S AUDITORY PROBLEMS CHECKLIST FOR AUDITORY PROCESSING EVALUATION}

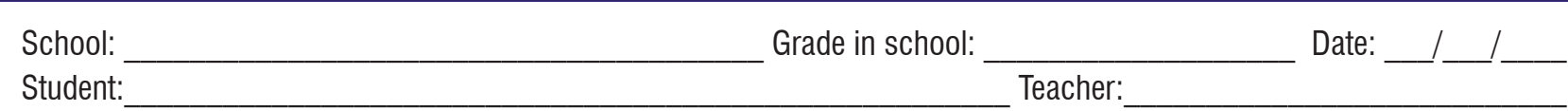

The QFISHER identifies the auditory behavior based on the teachers' perception and provides data on behavioral difficulties manifested in everyday routine. It aims to establish relevant evidence that might indicate signs of disorders related to auditory processing. The QFISHER total score is 24 points - one point for each item checked. If 7 or more items are checked (28\%) the child is considered at risk of auditory processing disorder and the required procedure is an auditory processing assessment.

\section{INSTRUCTIONS: Check with an " $x$ " each item that you relate to the child's behavior.}

1. Does not pay attention (listen) to $50 \%$ or more of the instructions.

2. Does not listen attentively to the instructions - they have to be repeated many times.

3. Says: "Huh?" and "What?" at least five times.

4. Cannot focus on auditory stimuli for more than a few seconds.

5. Has short attention spans (check the corresponding span): 0-2 minutes; 2-5 minutes; 5-15 minutes; 15-30 minutes

6. Sometimes daydreams (distraction).

7. Gets easily distracted with background noise.

8. Has difficulties with the language sounds. What reading method is used?

9. Has problems discriminating sounds.

10. Has difficulties remembering the sequence they heard from someone.

11. Forgets what was said a few minutes before.

12. Does not remember simple thigs from their everyday routine.

13. Has problems remembering what they heard in the previous week, month, year.

14. Has difficulties following auditory instructions.

15. Often does not understand what is said.

16. Does not understand many words - verbal concepts for their age / grade in school

17. Responds slowly or late to verbal stimuli.

18. Has language problems (morphology, syntax, vocabulary, phonology).

19. Has articulation problems (phonology - difficulty with expressive speech sounds).

20. Cannot always relate what they hear with what seems to be.

21. Learns little by hearing.

22. Lacks learning motivation. Does the behavior observed reinforce this concept?

23. Has a performance below the average in one or more areas.

24. Has difficulties with reading comprehension.

COMMENTS:

\begin{tabular}{|c|c|c|c|c|c|}
\hline CATEGORY & $\begin{array}{c}\text { QFISHER (9 points) } \\
\text { Hearing }\end{array}$ & $\begin{array}{c}\text { QFISHER (5 points) } \\
\text { Attention }\end{array}$ & $\begin{array}{c}\text { QFISHER (3 points) } \\
\text { Memory }\end{array}$ & $\begin{array}{c}\text { QFISHER (4 points) } \\
\text { Language }\end{array}$ & $\begin{array}{l}\text { QFISHER (3 points) } \\
\text { School performance }\end{array}$ \\
\hline Respective Questions & $\begin{array}{c}2,3,8,9,10,14,17 \\
20 \text { e } 21\end{array}$ & $1,4,5,6,7$ & $11,12,13$ & $15,16,18,19$ & $22,23,24$ \\
\hline \multicolumn{6}{|l|}{ Sum of the Categories } \\
\hline QFISHER - TOTAL & & & & & \\
\hline
\end{tabular}

*QFISHER analysis per category proposed by CIBIAN and PEREIRA (2014). 